lightly touched with the nitrate of silrer. The compress was accurately adjusted in the wound, and secured by a turn or two of the roller; the slowing compresses (again consisting of two halves of a phial cork covered with lint) were then applied, and kept in sittit by a turn or two of the bandage. The tourniquet was gradually slackened, and the efiect watehed. The hæmorrhage was now completely arrested, and the man soon felt quite comfortable, at once admitting the great superiority in the style of dressing.

Next day, in consequence of considerable subsidence of in. flammatory swelling, the whole apparatus was becoming loose. There was, however, no return of bleeding, which was certainly rather remarkable. I put on an additional roller to re-secure the former appliances. All went on well. Four days subsequently, the apparatus again becoming loose, 1 thought it might be safely removed. I did so, leaving the compress radually to work its own way out of the wound as it might become loosened by the discharges. The swelling of the hand had materially abated. Two deep indentations existed at the site of the slowing compressors. Pus was oozing from the wound, but there was not even a stain of blood. The wound was treated with simple warm-water dressing, and injunctions were given, in case of recurrence of hæmorrhage, to keep a sponge tirmly pressed upon the bleeding point until my arrival. Not a single bad symptom presented itself afterwards, and the man steadily recovered.

CASE 3.-J. C- aged seventeen, mariner's apprentice. While descending the hold at sea, a heavy stanchion which served as a hand-rail gave way, and he, with it, fell upon the ballast in the bottom of the vessel, a distance of several feet. His right hand was crushed between the stanchion and a large angular piece of chalk. The metacarpal bones of the middle and ring fingers were fractured, and a severe contused and lacerated wound of the palm was inflicted. No bleeding of consequence occurred at the time. The hand was rolled up by some of the lad's comrades, and he remained at sea two days. Upon my seeing him, I recommended water dressing, and a splint to be applied at the back of the hand. The case progressed favourably for three days, when some constitutional disturbance showed itself, the hand inflamed, swelled immensely, and the palm became infiltrated with pus. During the night brisk hæmorrhage occurred, which soaked the bed-clothes and rendered the lad quite faint. I was sent for, and attended immediately. The bleeding was still continuing, welling out freely from a most unhealthy-looking wound. The brachial was compressed with a tourniquet, as an immediate step; the wound was wiped out clean, and explored carefully to detect, if possible, the bleeding point, but it could not be found. The case looked as unproinising a one to treat by compression as could well be conceived, from the enormous tumefaction and apparent intolerance of pressure which must have existed. I determined, however, on its adoption, and applied it in the usual way. No tightness was really required; the dressing was in every respect comfortable, the hæmorrhage perfectly controlled, and not one drop more blood was lost. The dressings were removed in two days; the plug separated with the discharge; and in about a fortnight the wound healed. The fractured bones became consolidated; and, with the exception of a little bulging at the back, and stiffness of the fingers, which will eventually pass off, the cure is complete.

Remarks. - The special question connected with this subject requiring consideration is, Will this mode of treatment a vail in all cases of wound of the palmar arch? In order to discuss this conveniently, I shall offer a few observations upon primary and secondary hromorrhage from palmar wounds, and nots its application to each of these separately.

Liston says, that in cases of primary hæmorrhage, "instead of trusting to pressure, which is not always well or efficiently applied, almost uniformly disappoints expectation, and leads to a severe form of inflammatory action, it is better at once to enlarge the wound, and tie the wounded vessel above and below the wounded part." This is undoubtedly true as regards hæmorrhage from arterial wounds renerally, and, considered in connexion with the ill effects resulting from that injuliciou form of pressure adopted in the cases under special notice, had the greater weight, and recommended itself all the more forcibly; but if it can be shown that, by a simple modification, no violent pressure at the wound is necessary, and consequently that all this apprehended danger may be avoided, the argument does not apply. I am certain it may be laid down as a surrical axiom, that in all cases of uncomplicated primary hæinorrhage from the palm, exploration for the wounded ressel, if requiring any incisions of severity, or painfui dissection, is entirely un- necessary; compression of the arterial trunks on the cardiac aspect can be easily and effectually applied, and the slightest amount only of pressure is requisite at the wound to control the hremorrhage completely.

Cases of secondary homorrhage are those in which this mode of treatment would perhaps be expected more frequently to fail. Liston says of such, "The main artery is to be obstrueted at a distance from the wounded part," and this expresses the prevalent and generally-entertained opinion. The mode of carrying out this indication which immediately presented itself to Liston's mind as most easy and effectual was that by deligation of the brachial. We have seen that this practice is unwarrantably severe and highly hazardous, and further, that it is unnecessary, inasmuch as all that it can accomplish may be obtained by simpler and safer means. But it may be urged that under many circumstances of this kind there is great intolerance of pressure, and that it thus may fail. This is a mere chimera, and in practice will not occur. The pressure required, in consequence of being subdivided, is really so slight in degree, the points for applying it capable of being so variously chosen, and easily shifted, that it need never be productive even of any discomfort. I unhesitatingly affirm, that the practice proposed will be found completely effectual in this whole class of cases, and feel assured that it will, however objectionable it may be to the cultivators of ostentatious surgery, eventually entirely supersede the harsher and more dangerous practice of deligation. Gorleston, 1858.

\section{REPORT OF A CASE \\ oF}

\section{OBSTRUCTION OF THE BOWELS.}

BY T. H. TANNER, M.D., \&c.

TuE following case seems to present one or two features of so much interest, that no apology need be offered for briefly reporting it.

On Thu'rsday, the 2nd of September, I was sent for by $\mathbf{M r}$. H. J. Rad̈cliffe, of Brentford, to see a patient who had been under his are for some days suffering from an attack of ileus. The history was as follows:-M. A. B--, aged fifty-nine, single; has ai ways led an active life, and has usually enjoyed very good health. Two days before last Christmas she had a severe attack of jaundice, attended with fever, violent sickness, and great pain over the liver. She refused to see any medical man, and did not take medicine of any kind; but at the end of a few days 'was apparently well. From this date until the 26th of August, she was in good health; sleeping well at night, taking plenty of exercise, enjoying a very good appetite, and having her bowels moved regularly and naturally. On the morning of the last-mintioned day she felt quite strong; her bowels were properly o pened, she took a moderate walk, and made a hearty dinner at one o'clock P.M. Five hours subsequently, however, she was seized with an attack of nausea and vomiting, which continuea', at intervals, throughout the night On the next morning her bowels acted again, though not freely; the sickness continued during the day, through the ensuing night, and on the following morning. At this time-August 28 th-the matters vomited were abundint, and assumed a fæcal character, and Mr. Radcliffe was then called in. This gentleman at once diagnosed the existence of some obstruction, but thought it right to try the effect of purgatives. Agents of various kinds were carefully employed, without any effect, until my visit; the bowels remaining unacted upon, and the stercoraceous vomiting persisting.

On examining the patient, just one week after the commencement of the attack, I found her rather irritable, and much depressed, with a pulse of 130 ; the ton gue was thickly furred, and the breath offensive; there tvas tornenting thirst; she had had no sleep for several nights; there w as flatulent distention of the abdomen, with pain and tenderress, especially in the left hypochondriac region; there was no hernial protrusion, and she had never had any rupture; and the ux inary secretion was natural in quantity. The indications for treatment seemed clearly to point to the necessity of administering opium to alleviate pain and restrain secretion; together $w^{\text {ith }}$ abstinence from food, and especially from fluids: Hence, one grain of opium was given every four hours; sedative fom entations were applied to the abdomen; ice was susked to check the thirst; 
and a small quantity of arrowroot, with brandy, was allowed. It seemed useless to lay much stress upon the diagnosis of the exact seat of the obstruction, inasmuch as the early occurrence of the frecal vomiting appeared to point to its existence being high up; whilst, on the contrary, the free secretion of urine tended to show that absorption was going on from a large sur. face of intestine.

On the following day the painful symptoms rere somewhat mitigated. The pain was nearly gone, the vomiting had almost ceased, she had enjoyed some sound sleep, and was much less depressed. Under these circumstances, it was thought proper to try the effects of a large enema; consequently a stomachpump tube was passed to the extent of twenty-five inches, and two or three pints of fluid, with castor oil, turpentine, \&c., were injected. No facal matter was brought away, and the remedies ordered the previous day were directed to be continued, together with the application of some mercurial ointment to the abdomen. Of course, the propriety of opening the abdomen, as has been so frequently unsuccessfully practised, was fully discussed in one or two consultations; but it was concluded that there was nothing to justify such a proceeding, since there was no definite clue either to the cause or to the seat of the obstruction.

To detail the further progress of this unfortunate case seems unnecessary. Suffice it to say that the bad symptoms all returned; that everything was done to relieve pain, \&c., that careful nursing and assiduous attention on the part of $\mathrm{Mr}$. Radcliffe could effect; but that the patient sank and died on Friday, September 10th, at six o'clock P.M.

Twenty-two hours after death the body was examined by Messrs. Radcliffe and Brown, Dr. Daldy, of Broad-streftbuildings, and myself, being present. Before opening the peritoneal cavity thoroughly, an exploratory incision was made, and the hand introduced, to endeavour to discover the sfat of obstruction. The attempt, however, failed. On laying; open the abdomen, the intestines were seen very much distended, and their walls congested; many of the coils were ulightly glued together by recently-effused lymph. On unravelling the canal, the obstruction was found to consist of a very hard mass, the size of a large walnut, wedged tightly into the ileum, just six inches above the cæcum. Below the obstruction the intestines were empty, and healthy; above it, they were distended by a large quantity of a yellow, pultaceous, fæeal matter, sufficient, when removed, to almost fill an ordinary wash-hand basin. The coats of the ileum at and about the seat of the concretion were much atrophied, but there was ro ulceration. The concretion, on being subsequently cut through with a saw, was found to consist essentially of a gall-store; the nucleus being composed of cholesterine, around which animal matter had been gradually but very firmly deposited in layers.

0 ) reviewing the facts which have now been detailed, two points only seem to require notice, and ther are these:-First, that although in such a case no remedies could avail much to save life, yet marked relief can be affordes by means of opium. Second, that when a patient suffers from jaundice, produced by the passage of a gall-stone, great cure ought to be taken that this concretion is afterwards remored from the alimentary tube by the free exhibition of purgatives; and since the retention of such a foreign body may, as; in this case, ultimately produce death, so we ought not to rest satisfied until we have found it in the evacuations.

Charlotte-street, Dedford-square, October, 1858.

\section{ON DISEASE USUALLY REFERRED TO THE LUNGS OF: STOMACH.}

By GEORGE GREGORY, EsQ., M.R.C.S., Bolton-le-Moors.

M. B - , aged forty-six, housekeeper, has had nine children, six of whom are living and healthy. Her father died at the age of sixty-six from "bad cough." Her mother is living and healthy. The patient, enjoyed good health until about sixteen years ago, when during the summer she had difficulty of breathing, which continued about three months, and was then succeeded by a ccugh, and ultimately a viscid expectoration, which gave a lit.tle relief. She had scarcely been free from these symptoms during a period of fire years, when, about ten years ago, she suffered. from pain in the stomach and vomiting, which seemed. to subside spontaneously in about three weeks from its commencement. At the termination of these symp. toms, the pulmonary affection again alternated with the gastric derangement, and she assures me that for the whole of the last ten years these charges have been rung with scarcely any cessation, and with little relief from medicine.

Present state, Nov. 1857.- Is rather thin, but not anæmic ; complains of pain in the stomach, (not confined to one spot,) and vomiting, which causes great depression. She gasps at intervals, as though afflicted with emphysema. On pressing the epigastrium there is no tenderness; there are no febrile symptoms. Ou percussing the chest, the sounds are normal, and the stetb.oscope reveals nothing, except perhaps increased respiratory artion; the bowels are regular, and the catamenia have not yet ceased. There is no spinal tenderness. Restricting the dietary to a little milk-and-water every three hours, I gave her successively an effervescing mixture with morphia, a mixture of hyposulphite of soda with morphia, and afterwards sedatives and antispasmodics; but these means, with counterirritation to the stomach, appeared useless. On re-considering the history, I thought, from the alternating symptoms, there must be some abnormal state about the origin of the pneumogastric nerves, and accordingly I ordered a blister to the nape of the neck. On my next visit I was astonished to find that the pain and romiting had ceased. She continued to enjoy good health until March last, when the pulmonary affection again manifested itself. I could not detect anything unusual in the chest sounds. The cough was loud and brazen; it would have been called a stomach cough by some of the older writers. The expectoration was both viscid and abundant, and its viscidity continued, notwithstanding that I gave antimonial wine, with ipecacuanha wine, both in expectorant and emetic doses, and afterwards stimulating expectorants ; but a blister applied to the neck gave great relief.

Cases of centric disease like the foregoing are rare, and con. sequently I have thought it right to add my quota towards the number that statistical evidence requires.

Westhoughton, October, 1858.

ON

\section{A CASE SIMULATING POISONING.}

By W. H. MOOR, Esq., M.R.C.S., Herts.

A. L_, aged sixty, a dark-complexioned woman, of melancholic temperament, whose general state of health had for years been indifferent, but of whose previous history little could be learnt, further than that of late years she had been subject to severe attacks of pain in the abdomen. When I first visited the patient, she was in a comatose condition, the only sign of consciousness shown being a motion as though $I$ gare her pain when I pressed on the epigastric and right hypochondriac regions. The previous day she had complained of pain in those regions, and had vomited violently. Previously she had been much as usual. The surface of her body was cold, the extremities especially so; no pulse at the wrist; beat of the carotids scarcely perceptible; heart sounds very faint; pupils dilated and fixed; abdomen not unusually larce, but on carefully percussing I could distinguish the liver extending somewhat beyond its normal boundary. There was no discoloration of the skin or the eye. In a few hours she died. Her husband and family had not the best of characters, and had shown great carelessness in applying for medical aid, not calling me in until she was dying. Altogether there seemed reason for suspecting foul play. I made an examination of the body, and here is the

A utopsy. - On opening the abdomen, no peritonitis was found, but the liver was large, extending from one to two inches below its normal position, and gorged with bile. On puncturing it with the point of the scalpel, bile flowed freely from the wound. The gall-bladder was distended with bile, as also were the ducts. The ductus communis choledochus, for a short distance from its opening into the duodenum, was thickened and indurated; and behind this induration were six biliary ealculi, the foremost one being very large. There was nothing further worthy of note.

Death, in this case, commenced at the heart. The coma. tose condition I consider was entirely depeudent upon the obstructed circulation, for she was not quite unconscious when I saw her, and then khe was almost dead; but the beat of the 